Smith, E. E. B., Milus, G. T., Austrian, R. \& Bernheimer, H. P. (1960). J. gen. Microbiol. 22, 265-271

\title{
Uridine Pyrophosphoglucose Dehydrogenase in Capsulated and Non-capsulated Strains of Pneumococcus Type I
}

\author{
By EVELYN E. B. SMITH* AND G. T. MILLS* \\ Biochemistry Department, The University of Glasgow, Scotland \\ AND R. AUSTRIAN AND HARRIET P. BERNHEIMER \\ Department of Medicine, State University of New York College of Medicine \\ at New York City, Brooklym 3, N.Y., U.S.A.
}

SUMMARY: A method is presented for the estimation of uridine pyrophosphoglucose dehydrogenase activity in extracts of pneumococci; this utilizes ${ }^{14} \mathrm{C}$-labelled uridine pyrophosphoglucose (UPPG). This method overcomes the difficulty of the spectrophotometric assay caused by the presence of reduced diphosphopyridine nucleotide (DPNH) oxidase in such extracts. An investigation was made of the protective effects of catalase and thioglycollate on pneumococcal UPPG dehydrogenase. Both these substances prevented inactivation of this enzyme. The results suggest that inactivation is caused by hydrogen peroxide and that the point of attack on the enzyme is upon sulphydryl groups. The UPPG dehydrogenase activity of some capsulated and non-capsulated strains of type I pneumococcus was determined. The capsulated and some of the non-capsulated strains examined had considerable UPPG dehydrogenase activity except one strain which had negligible activity. The enzyme UPPglucuronic acid-4-epimerase from a type I pneumococcus required diphosphopyridine nucleotide for activity.

The type specific capsular polysaccharides of some pneumococcal types are known to contain uronic acids (Heidelberger, 1958; Brown, 1989); that of type I, for example, contains galacturonic acid while those of types II, III and VIII contain glucuronic acid. It is becoming increasingly evident that the uridine pyrophosphouronic acid compounds are involved in the synthesis of these uronic acids before their incorporation into the capsular polysaccharides. Uridine pyrophosphoglucuronic acid (UPPGA) has been isolated from types II and III pneumococci (Smith, Mills \& Harper, 1957 a) and Smith, Mills \& Harper $(\mathbf{1 9 5 7} b)$ subsequently isolated uridine pyrophosphogalacturonic acid (UPPGalA) from a capsulated type I pneumococcus. It was shown by Smith, Mills, Bernheimer \& Austrian (1958a) that UPPGA was formed in a type II strain from uridine pyrophosphoglucose (UPPG) by the diphosphopyridine nucleotide (DPN)-dependent enzyme, UPPG dehydrogenase. Smith, Mills, Bernheimer \& Austrian (1958b) also showed that a capsulated type I pneumococcus contained the enzyme uridine pyrophosphoglucuronic acid-4epimerase (UPPGA-4-epimerase) which catalysed the conversion of UPPGA to UPPGalA. The importance of these two enzymic steps in the pathway of

* Present address: Department of Medicine, State University of New York College of Medicine at New York City, Brooklyn 8, N.Y. 
capsular synthesis in type $I$ pneumococcus and in the phenomenon of double capsulation was pointed out by Austrian, Bernheimer, Smith \& Mills (1958). Smith, Mills, Bernheimer \& Austrian (1959) reported that the instability of UPPG dehydrogenase activity in extracts of a non-capsulated strain of pneumococcus type II was due, probably, to the production of hydrogen peroxide by such extracts. Neill \& Avery $(1924 a, b)$ demonstrated that certain carbohydrases of pneumococcus were readily inactivated by peroxides. Austrian \& Colowick (1953) found that the inhibition of the fermentation of inulin and salicin by certain strains of pneumococcus under conditions permitting the formation and accumulation of perioxides was prevented by adding catalase. It was decided, therefore, to investigate the protective effect of catalase and thioglycollate on UPPG dehydrogenase activity. It also appeared desirable to know whether the loss of ability to produce capsular polysaccharide by certain strains of pneumococcus type $I$ was due to a deficiency of UPPG dehydrogenase or of UPPGA-4-epimerase. To this end, the activity of UPPGA dehydrogenase in extracts of a number of capsulated and non-capsulated strains of pneumococcus type I was determined. A method for the measurement of UPPG dehydrogenase activity is presented which overcomes the difficulties of the spectrophotometric assay of Strominger, Kalckar, Axelrod \& Maxwell (1954) which were caused by the very active DPNH oxidase found in the pneumococci. In additinn, evidence is presented to show the dependence of the activity of UPPGA-4-epimerase upon DPN.

\section{METHODS}

Strains of pneumococcus. In the experiments described, the following strains of pneumococcus were used; the nomenclature of the pneumococcal variants is that described by Austrian \& Bernheimer (1959) and Austrian, Bernheimer, Smith \& Mills (1959).

SI phenotypes: SVI and I41 S;

S-I phenotypes: $S_{-I_{1}}$ a non-capsulated mutant derived from strain I41S;

$S-r_{2}$ a non-capsulated mutant derived from strain ID;

$\mathrm{S}_{\mathrm{I}_{3}}$ a non-capsulated mutant derived from strain SVI.

Another strain, $S_{-r_{1}}$, transformed to capsular type I with transforming principle from strain $S_{I_{2}}$, was also used; this strain will be designated $S_{-I_{1}} \operatorname{TI}\left(S_{r_{2}}\right)$. A strain obtained by spontaneous mutation of $S_{-r_{2}}$ to SI will be referred to as such.

Growth of organisms and isolation of enzymes concerned with uridine pyrophosphoglycosyl metabolism. The methods were those of Smith et al. (1959).

Preparation of ${ }^{14} \mathrm{C}$-labelled $U P P G$ was carried out as described by Smith et al. (1959). The UPPG so obtained had a specific activity of $3 \cdot 3 \mu \mathrm{c} . / \mu \mathrm{mole}$, the radioactivity being located entirely in the glucose portion of the molecule.

Assay of UPPG dehydrogenase activity. Pneumococci from a $500 \mathrm{ml}$. culture were harvested during the logarithmic phase of growth (Smith et al. 1959). With strain SVI, high-speed centrifugation at $15,000 \mathrm{~g}$ for $30 \mathrm{~min}$. at $0^{\circ}$ was 
required to pack the cocci adequately. All other strains were harvested readily by centrifugation at $2000 \mathrm{~g}$ for $20 \mathrm{~min}$. at $0^{\circ}$.

Cell-free extracts of enzyme were prepared by the Celite $/\left(\mathrm{NH}_{4}\right)_{2} \mathrm{SO}_{4}$ fractionation technique (Smith et al. 1959); a composite fraction eluted from the Celite filter-cake between $3.0 \mathrm{M}-\left(\mathrm{NH}_{4}\right)_{2} \mathrm{SO}_{4}$ and $1.0 \mathrm{M}-\left(\mathrm{NH}_{4}\right)_{2} \mathrm{SO}_{4}$ was used as the enzyme extract. Such extracts contained the total dehydrogenase activity of the disrupted pneumococci and were free from phosphatases and pyrophosphatases which acted upon uridine pyrophosphoglycosyl compounds.

UPPG dehydrogenase assays were conducted as follows. A mixture of ${ }^{14} \mathrm{C}$-labelled UPPG (1.3 $\mu$ mole), $1 \mu$ mole diphosphopyridine nucleotide (DPN) a standard amount of enzyme extract determined by estimation of protein and 0.1 M-tris (2-amino-2-dimethylhydroxypropane-1 : 3-diol) buffer (pH 9-1) to a final volume of $2.5 \mathrm{ml}$. was incubated at $22^{\circ}$ for 30 min. The reaction was stopped by adding $10 \%(\mathrm{v} / \mathrm{v})$ perchloric acid to a final concentration of $1 \%$. The precipitated protein was removed rapidly by centrifugation at $0^{\circ}$ and the nucleotides which remained in the supernatant fluid were adsorbed with Norite and prepared for chromatography as described by Smith \& Mills (1954). An investigation of the adsorptive capacity of Norite under such conditions showed no preferential adsorption or elution of pure UPPG or UPPGA from mixtures.

The nucleotides were chromatographed in the neutral ethanol + ammonium acetate solvent of Paladini \& Leloir (1952) for 22-24 $\mathrm{hr}$; ; pure UPPG and pure UPPGA were used as markers. In each reaction the ultraviolet (u.v.) absorbing bands corresponding to UPPG and UPPGA were cut from the chromatogram and eluted quantitatively with distilled water by descending chromatography. Samples of the paper eluates were put on disks and counted at infinite thinness with a thin mica end-window Geiger counter.

Uronic acid epimerase assay. The presence or absence of the uronic acid epimerase catalysing the conversion of UPPGA to UPPGalA was determined by the method of Smith et al. (1958b).

Protein determinations were carried out by the spectrophotometric method of Warburg \& Christian (1941).

UPPG (98\% purity), UPPGA (98\% purity) and DPN (95\% purity) were obtained from Sigma Chemical Company, U.S.A. Crystalline catalase was obtained from Worthington Biochemicals, U.S.A. Thioglycollic (thiolacetic) acid (Analar) was obtained from British Drug Houses Ltd.

\section{RESULTS}

The effect of catalase and potassium thioglycollate on UPPG dehydrogenase activity

In a study of the UPPG dehydrogenase activity of Streptococcus pneumoniae strain R 19, derived from capsular type II, Smith et al. (1959) observed the marked instability of this enzyme and the low yields of UPPGA obtained with the experimental conditions used. It was considered possible that the low dehydrogenase activity might be a function of inactivation of the enzyme 
by hydrogen peroxide $\left(\mathrm{H}_{2} \mathrm{O}_{2}\right)$. This hypothesis would imply that sulphydryl groups were necessary for enzymic activity. The following experiments with strain I41S show that catalase or potassium thioglycollate was effective in protecting dehydrogenase activity during fractionation of pneumococcal enzymes.

The protective effect of catalase was examined by having this enzyme present during the whole course of the fractionation of the pneumococcal enzyme. To achieve this end, 5 units of crystalline catalase were added at each of the following stages of fractionation: (a) during disintegration of the cocci; $(b)$ at the time of the preliminary $3 \mathrm{M}-\left(\mathrm{NH}_{4}\right)_{2} \mathrm{SO}_{4}$ precipitation of protein; (c) to the 1.0 M- $\left(\mathrm{NH}_{4}\right)_{2} \mathrm{SO}_{4}$ eluate from Celite; $(d)$ before dialysis. The amount of protein contributed by the 20 units of crystalline catalase added was negligible when compared to the total protein of the enzyme extract and no correction was necessary for results expressed in Table 1.

Table 1. The protective effect of catalase and of thioglycollate on the UPPG dehydrogenase activity of pneumococcus strain I41S

\begin{tabular}{|c|c|c|c|c|}
\hline Treatment & $\begin{array}{c}\text { Ratio: } \\
\text { c./min. UPPGA } \\
\text { c./min.UPPG }\end{array}$ & $\begin{array}{c}\text { UPPGA } \\
\text { formed } \\
\text { (m } \mu \text { mole) })\end{array}$ & $\begin{array}{l}\text { m } \mu \text { mole } \\
\text { UPPGA/mg. } \\
\text { protein }\end{array}$ & $\begin{array}{l}\text { Relative } \\
\text { activity }\end{array}$ \\
\hline None & 0.009 & 12 & 0.7 & 3 \\
\hline $\mathrm{KCl}(0.01 \mathrm{M})$ & 0.021 & $\mathbf{2 6}$ & $1 \cdot 6$ & 6 \\
\hline Catalase & 0.091 & 104 & $6 \cdot 2$ & 24.5 \\
\hline Catalase $+\mathrm{KCl}$ & 0.280 & 278 & $16 \cdot 3$ & $64 \cdot 4$ \\
\hline $\mathrm{K}$ thioglycollate & 0.300 & 288 & $25 \cdot 3$ & 100 \\
\hline
\end{tabular}

To study the protective effect of potassium thioglycollate (thioglycollic acid adjusted to $\mathrm{pH} 7 \cdot 0$ with $\mathrm{KOH}$ ) the latter was maintained at $0.01 \mathrm{M}$ during disintegration of the organisms and during enzyme fractionation. The final protein precipitate was dialysed against $500 \mathrm{ml}$. 0.01 M-thioglycollic acid neutralized with $1 \mathrm{ml} .5 \mathrm{~N}-\mathrm{KOH}$ to $\mathrm{pH}$. During dialysis there was an isoelectric precipitation of protein which readily redissolved at the $\mathrm{pH}$ value

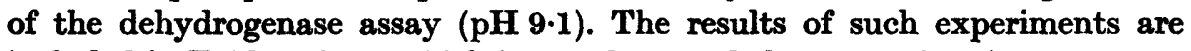
included in Table 1 from which it may be noted that potassium ion at $0.01 \mathrm{~m}$, in the presence and in the absence of catalase, effected a twofold increase in dehydrogenase activity. The effect of other ions was not studied. Since potassium thioglycollate was the most effective protective agent for the UPPG dehydrogenase activity, all subsequent assays of this enzyme in various strains of type I pneumococcus were carried out with thioglycollate present as described.

UPPG dehydrogenase activity of type I pneumococcal variants

The activity of UPPG dehydrogenase in the pneumococcal variants under study is summarized in Table 2.

\section{The DPN requirement of UPPGA-4-epimerase}

In the determination of the ability of pneumococcal extracts to catalyse the conversion of UPPGA to UPPGalA, DPN was added to the enzyme reaction. The addition of DPN (Smith et al. 1958b) was based primarily on the 
assumption that the reaction was analogous to the DPN-dependent conversion of UPPG to UPPgalactose described by Maxwell (1956). To test this premise, $\mathbf{3 0 0 0}$ units of highly purified DPNase (Carlson, Kellner, Bernheimer \& Freeman, 1957; kindly supplied by Dr A. W. Bernheimer, Department of Microbiology, New York University College of Medicine) were added to a reaction mixture containing $4 \mu$ mole UPPGA, $2 \cdot 0 \mathrm{ml}$. enzyme extract obtained from strain I $41 \mathrm{~S}$ and $1.0 \mathrm{ml}$. tris buffer (pH 7.8). Subsequent stages of the reaction were carried out as described (Smith et al. 1958b). No conversion of UPPGA to UPPGalA was demonstrated in the presence of the DPNase indicating an absolute requirement for DPN by the UPPGA-4-epimerase. Control experiments with added DPN (0.5 $\mu \mathrm{mole})$ showed the conversion of UPPGA to UPPGalA; when DPN was omitted slight but demonstrable conversion was evident. The latter result would indicate that a sufficient amount of bound DPN was present in the enzyme extract to enable the reaction to proceed to a limited extent.

Table 2. The UPPG dehydrogenase activity of several strains and variants of pneumococcus type I

\begin{tabular}{|c|c|c|c|c|}
\hline $\begin{array}{c}\text { Strain of } \\
\text { pneumococcus }\end{array}$ & $\begin{array}{c}\text { Ratio: } \\
\text { c./min. UPPGA } \\
\text { c./min. UPPG }\end{array}$ & $\begin{array}{c}\text { UPPGA } \\
\text { formed } \\
(\mathrm{m} \mu \mathrm{mole})\end{array}$ & $\begin{array}{c}\text { mpmole } \\
\text { UPPGA/mg. } \\
\text { protein }\end{array}$ & $\begin{array}{r}\text { Relative } \\
\text { activity }\end{array}$ \\
\hline  & $\begin{array}{l}0 \cdot 800 \\
0 \cdot 058 \\
0 \cdot 0016 \\
0 \cdot 0505 \\
0 \cdot 183 \\
0 \cdot 55 \\
0 \cdot 162\end{array}$ & \begin{tabular}{r|}
288 \\
70 \\
2 \\
60 \\
60 \\
153 \\
65 \\
174
\end{tabular} & $\begin{array}{c}25 \cdot 3 \\
8 \cdot 5 \\
0 \cdot 24 \\
8 \cdot 8 \\
15 \cdot 3 \\
22 \cdot 2 \\
27 \cdot 0\end{array}$ & \begin{tabular}{|c|}
100 \\
$38 \cdot 6$ \\
$0 \cdot 9$ \\
$34 \cdot 7$ \\
$60 \cdot 5$ \\
89 \\
107
\end{tabular} \\
\hline
\end{tabular}

\section{DISCUSSION}

The findings of Smith et al. (1957a,b), Smith et al. $(1958 a, b)$ and Austrian et al. (1958) indicate that the pathway of formation of galacturonic acid in Pneumococcus type I involves the oxidation of UPPG to UPPGA by means of UPPG dehydrogenase followed by the conversion of UPPGA by UPPGA-4epimerase to UPPGalA. It is clear, therefore, that these two enzymes are related to the synthesis of capsular polysaccharide by pneumococcus type $I$. Information concerning the properties and activity of these enzymes in variants of this organism may be of importance in understanding their behaviour.

In previous studies of UPPG dehydrogenase performed with enzyme derived from a non-capsulated strain (R19) of pneumococcus type II by Smith et al. (1959), the instability of the enzyme was noted and the conclusion drawn that this instability might be due to sensitivity to $\mathrm{H}_{2} \mathrm{O}_{2}$, which is produced by most strains of pneumococcus (Neill \& Avery, 1924 $a, b$; Austrian \& Colowick, 1953). In the present work it has been shown clearly (Table 1) that the presence of catalase during the extraction and fractionation of UPPG dehydrogenase from pnueumococci leads to a considerable increase in the amount of active enzyme obtained. The fact that thioglycollate gives the same result and an even higher degree of enzymic activity would suggest that 
UPPG dehydrogenase is dependent upon sulphydryl groupings for activity. These groups are oxidized easily by $\mathrm{H}_{2} \mathrm{O}_{2}$ and protected therefrom by catalase. It will be noted from Table 1 that $\mathrm{K}^{+}$ions caused an increase in activity, both alone and in the presence of catalase. Whether this ionic effect is related specifically to potassium or is a more general one requires further investigation.

The use of ${ }^{14} \mathrm{C}$-labelled UPPG for the estimation of UPPG dehydrogenase activity gives a method free from the interference caused by the DPNH oxidase which is present in all strains of pneumococci so far examined and which interferes with the use of a spectrophotometric assay dependent upon reduction of DPN. In the present method the ratio of radioactivity in UPPGA to that in UPPG gives a direct estimate of the amount of UPPGA formed. An examination of the ethanol + ammonium acetate developed chromatograms of the reaction mixtures for the presence of radioactive areas corresponding to free glucose and glucuronic acid and the corresponding 1-phosphates gave negative results, indicating that there was no breakdown of UPPG or UPPGA; these reactions might otherwise cause inaccuracies in the estimate of UPPG dehydrogenase activity.

In the experiments recorded in Table 2, the radioactivity of the UPPuronic acid fraction plus that of the unchanged UPPG was equal to that of the UPPG used as substrate. This finding would appear to indicate that incorporation of uronic acid into other materials did not occur.

The higher radioactivity in the UPPuronic acid fraction in the case of the strains I41S, SVI and $S_{I_{I_{2}}}$ reverted to SI, might be due to the further action of the UPPGA-4-epimerase which is present in these strains. No attempt was made to distinguish between UPPGA and UPPGalA in the experiments recorded in Table 2.

Certain non-capsulated strains of pneumococcus type $I\left(S_{-I_{1}}\right.$ and $\left.S-_{I_{3}}\right)$ still possess considerable UPPG dehydrogenase activity. These strains were shown by Austrian et al. (1959) to be deficient in UPPGA-4-epimerase; strain $\mathrm{S}_{-\mathrm{r}_{2}}$, which in the present work was found to lack UPPG dehydrogenase activity, did possess UPPGA-4-epimerase activity. The strain $S_{-r_{2}}$ on spontaneous reversion to the capsulated state regained considerable UPPG dehydrogenase activity and the capsulated type I strain recovered by Austrian \& Bernheimer (1959) following transformation of strain $S_{I_{1}}$ with DNA from $S_{-I_{2}}$ showed the same UPPG dehydrogenase activity as the original $S_{r_{1}}$ strain (Table 2). The present results emphasize the importance of UPPG dehydrogenase and UPPGA-4-epimerase in the pathway of capsular polysaccharide synthesis in type $I$ pneumococcus and show at the same time that a deficiency of one of these enzymes is not necessarily accompanied by a deficiency of the other.

One of us (E.E.B.S.) was the holder of a Senior Research Award of the Carnegie Institution of Washington during the course of this work. This investigation was supported in part by a grant from the Medical Research Council (Great Britain) and by research grant E-1018(C2) from the Institute of Allergy and Infectious Diseases, United States Public Health Service. The authors wish to thank Brian Galloway for excellent technical assistance. 


\section{REFERENCES}

Austrian, R. \& Bernhemer, H. P. (1959) Simultaneous production of two capsular polysaccharides by pneumococcus. I. Properties of a pneumococeus manifesting binary capsulation. J. exp. Med. 110, 571 .

Austrian, R., Bernheimer, H. P., Smith, E. E. B. \& Mmls, G. T. (1958). Acquisition of a new capsular type by pneumococcus, a multifactor transformation. Cold Spr. Harb. Symp. quant. Biol. 23, 99.

Austrian, R., Bernhenger, H. P., Smith, E. E. B. \& Mirus, G. T. (1959). Simultaneous production of two capsular polysaccharides by pneumococcus. II. The genetic and biochemical bases of binary capsulation. J. exp. Med. 110, 585.

Austrian, R. \& Colowick, M. S. (1953). Modification of the fermentative activities of pneumococcus through transformation reactions. J. exp. Med. 92, 875.

Brown, R. (1939). Chemical and immunological studies of the pneumococcus. V. The soluble specific substances of types I-XXXII. J. Immunol. 37, 445 .

Carison, A. S., Krillner, A., Bernhemer, A. W. \& Freeman, E. B. (1957). A streptococcal enzyme that acts specifically on diphosphopyridine nucleotide. Characterization of the enzyme and its separation from Streptolysin 0 . J. exp. Med. 106, 15.

Heidelberger, M. (1958). All polysaccharides are immunologically specific. In Symp. no. 1. Carbohydrate chemistry of substances of biological interest. 4th Int. Congr. Biochem. 1, 52.

Maxwell, E. S. (1956). Diphosphopyridine nucleotide, a cofactor for galactowaldenase. J. Amer, chem. Soc. 78, 1074.

NeILI, J. M. \& Avery, O. T. (1924a). Studies on oxidation and reduction by pneumococcus. VI. The oxidation of enzymes in sterile extracts of pneumococcus. J. exp. Med. 40, 405.

NemL, J. M. \& AVERY, O. T. (1924b). Studies on oxidation and reduction by pneumococcus. VII. Enzyme activities of sterile filtrates of aerobic and anaerobic cultures of pneumococcus. J. exp. Med. 40, 423.

Paladin, A. C. \& Leloir, L. F. (1952). Studies on uridine diphosphate glucose. Biochem. J. 51, 426.

Sмттн, E. E. B. \& Mrus, G. T. (1954). Uridine nucleotide compounds of liver. Biochim. biophys. Acta, 13, 386.

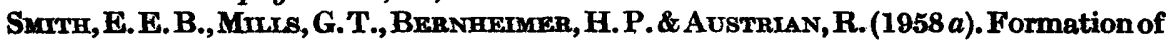
uridine pyrophosphoglucuronic acid from uridine pyrophosphoglucose by extracts of a non-capsulated strain of pneumococcus. Biochim. biophys. Acta, 28, 211.

Smrth, E. E. B., Mulus, G. T., Bernheimer, H. P. \& Austrian, R. (1958b). The presence of an uronic acid epimerase in a strain of pneumococcus type $I$. Biochim. biophys. Acta, 29, 640.

Simti, E. E. B., Murls, G. T., Bernheimer, H. P. \& Austrian, R. (1959). A study of some enzymes in extracts of a noncapsulated strain of pneumococcus concerned with uridine pyrophosphoglycosyl metabolism. J. gen. Microbiol. 20, 654.

Smith, E. E. B., Muls, G. T. \& HARPER, E. M. (1957 a). A comparison of the uridine pyrophosphoglycosyl metabolism of capsulated and non-capsulated pneumococci. J. gen. Microbiol. 16, 426.

Surth, E. E. B., Muls, G. T. \& HARPER, E. M. (1957 $b$ ). The isolation of uridine pyrophosphogalacturonic acid from a type I pneumococcus. Biochim. biophys. Acta, 23, 662.

Strominger, J., Kalckar, H. M., Axelrod, J. \& MaXwelx, E. S. (1954). Enzymic oxidation of uridine diphosphate glucose to uridine diphosphate glucuronic acid. J. Amer. chem. Soc. 76, 6411.

Warburg, O. \& Christian, W. (1941). Isolierung und Kristallisation des Gärungsferments Enolase. Biochem. Z. 310, 384.

(Received 10 August 1959) 